\title{
Editorial:
}

\section{Chronic or Late Lyme Neuroborreliosis: Present and Future}

\author{
Judith Miklossy*, Samuel Donta, Kurt Mueller, Oliver Nolte and George Perry
}

Alzheimer Research Center, Prevention Alzheimer International Foundation, 1921 Martigny-Croix, CP 16, Switzerland

This special issue gives a framework of an international effort, to critically and constructively overview the clinical and pathological aspects of Lyme neuroborreliosis and show directions for future practice and research.

The issue in the diagnosis and treatment of Lyme neuroorreliosis is assessed followed by a comprehensive analysis of the involvement of connective tissue and associated clinical manifestations. A critical review shows that both the meningovascular and meningoencephalitic forms, which define chronic or late neurosyphilis also occur in Lyme neuroborreliosis. Clinical and pathological confir-mation of these tertiary forms and detection of Borrelia burgdorferi in association with tertiary brain lesions were reported by many authors. These observations indicate that similarly to Treponema pallidum, Borrelia burgdorferi infection is directly involved in the late or chronic manifestations of Lyme neuroborreliosis. Chronic or late Lyme neuroborreliosis both refer to tertiary neuroborreliosis, therefore, the use of these terms as different entities is not justified and may lead to confusion.

A critical assessment of clinical trials will guide the design of future clinical studies and a detailed analysis of various factors influencing PCR detection of Borrelia specific DNA would be precious to improve the sensitivity of this potentially important diagnostic tool.

*Address correspondence to this author at the International Alzheimer Research Center, Alzheimer Prevention Foundation, 1921 Martigny-Croix, CP 16, Switzerland; Tel: + 4127722 0652, +41 79207 4442;

E-mail: judithmiklossy@bluewin.ch
An update on the virulence determinants of Borrelia burgdorferi and the pathomechanisms involved in Lyme disease is discussed followed by a review showing the importance of co-infections in the diagnosis and treatment of Lyme disease.

Evidence for an infectious origin of various neuropsychiatric symptoms of tick-borne diseases and various psychiatric disorders are also discussed. The involvement of immune system reactions, chronic inflammation, genetic and environmental factors are also considered. Finally an update on the perspectives on Lyme Borreliosis in Canada closes the special issue.

The majority of authors are internationally recognized neurologists and scientists with extensive experience and complementary expertise in clinical and/or basic research on Lyme disease. The exchange of knowledge at an international level and between experts in various branches of medicine and in basic research is the way to advance faster in this new, promising and important field of medicine. The aim of this special issue is to contribute to this process. This approach motivated the authors at the annual meeting of the German Borreliosis Society (Deutsche Borreliose-Gesellschaft, DBG) in 2011 at Wuppertal, Germany to initiate and realize this special issue.

This issue is dedicated to the memory of Mark A. Smith whose untimely death has left a void for those looking to novel ideas to solve chronic diseases.

(C) Miklossy et al.; Licensee Bentham Open

This is an open access article licensed under the terms of the Creative Commons Attribution Non-Commercial License (http://creativecommons.org/licenses/by-nc/3.0/) which permits unrestricted, non-commercial use, distribution and reproduction in any medium, provided the work is properly cited. 